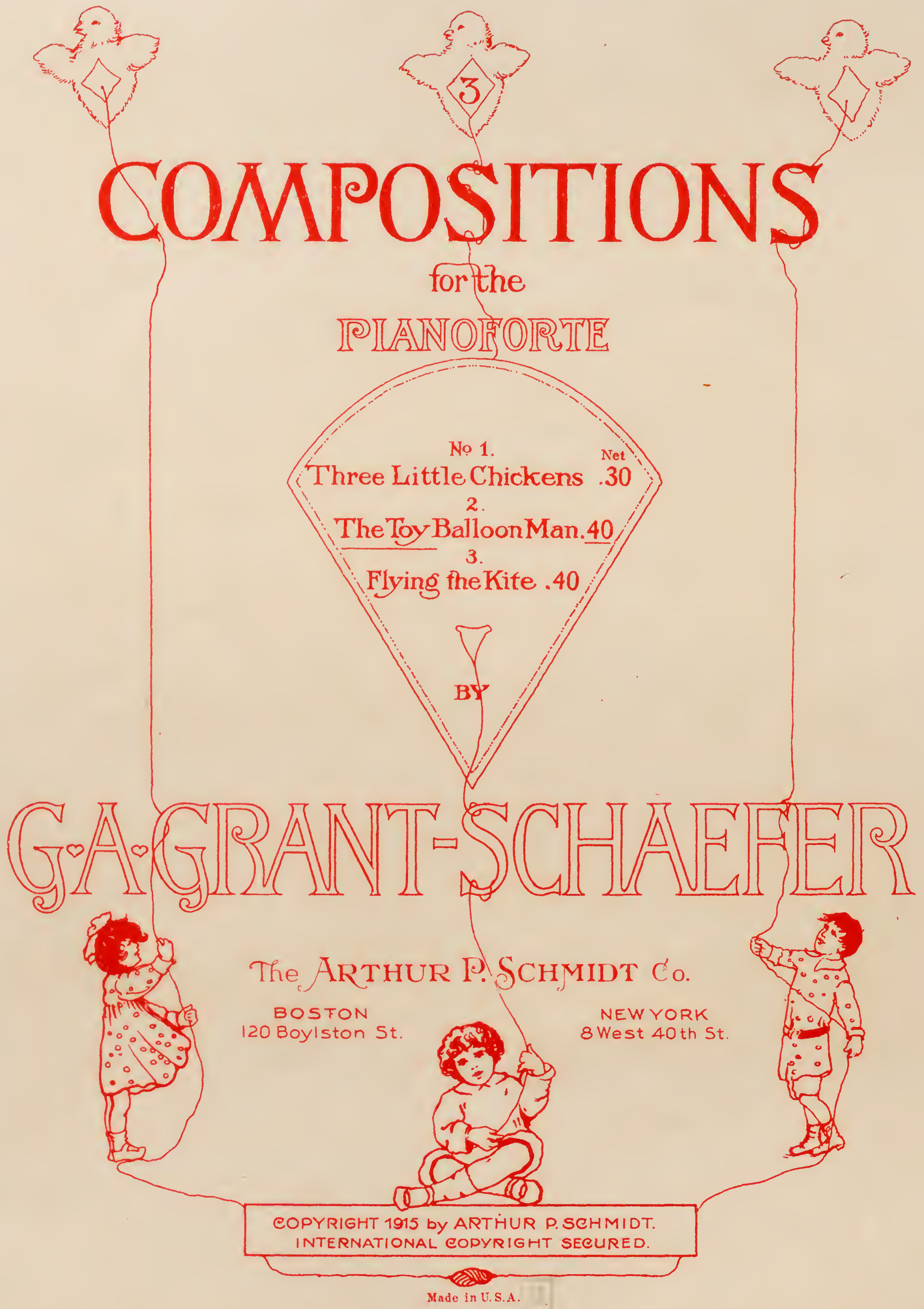





\section{The Toy Balloon Man}

See the little man

With balloons all bright and new;

I shall buy a red one

If you will buy a blue.

Allegretto

G. A. GRANT-SCHAEFER
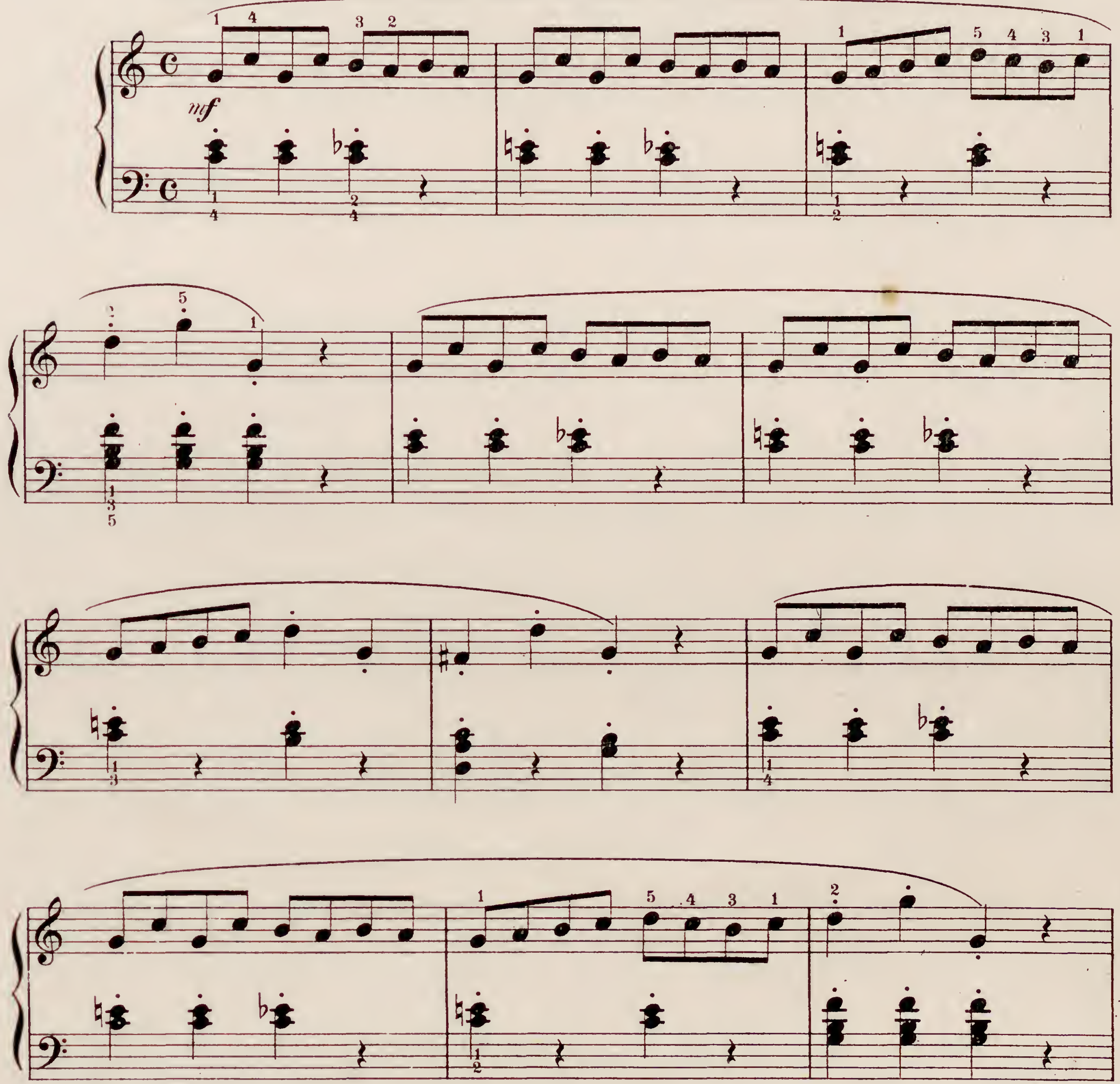
4
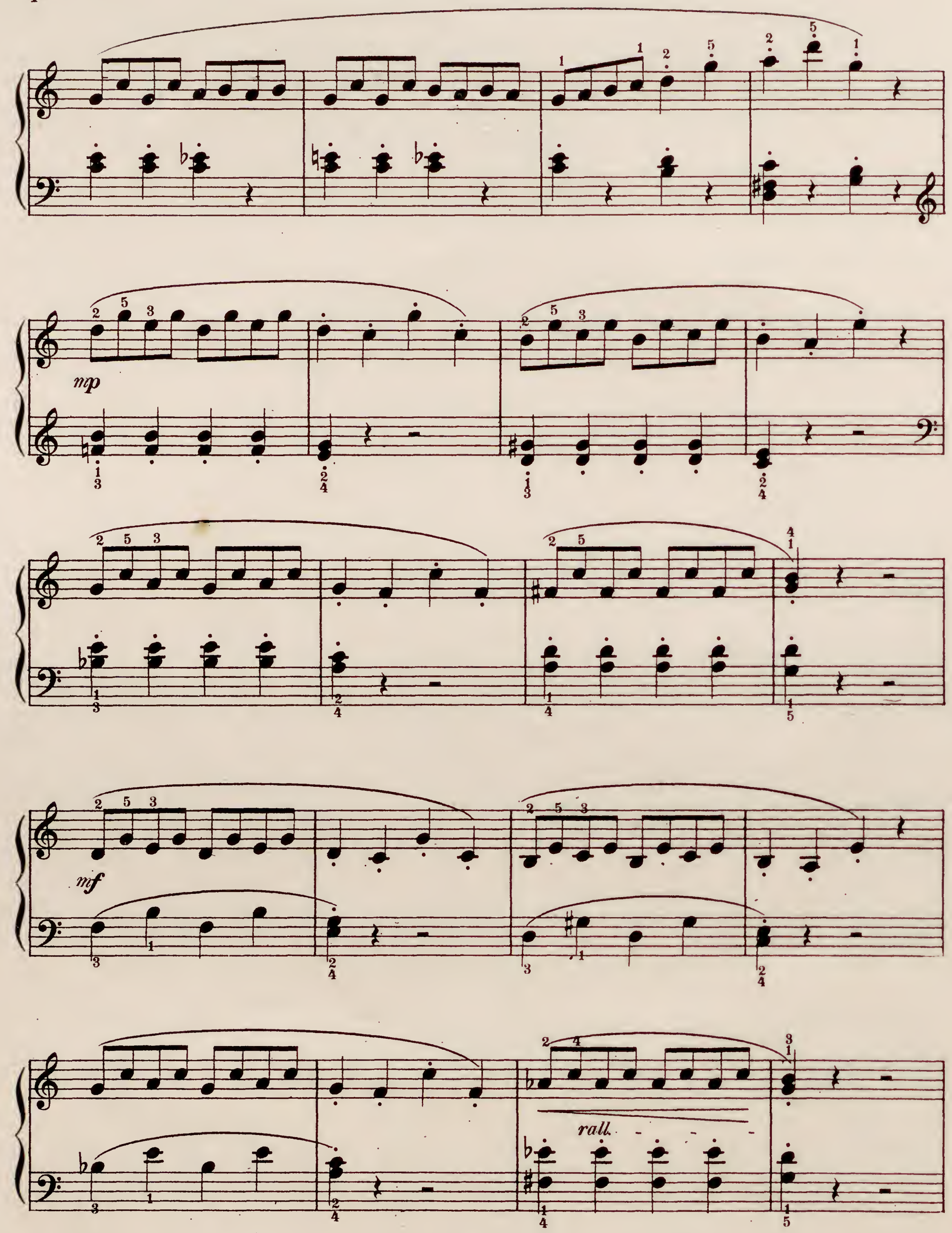

$$
\text { ค.P. 8. 10522-3 }
$$




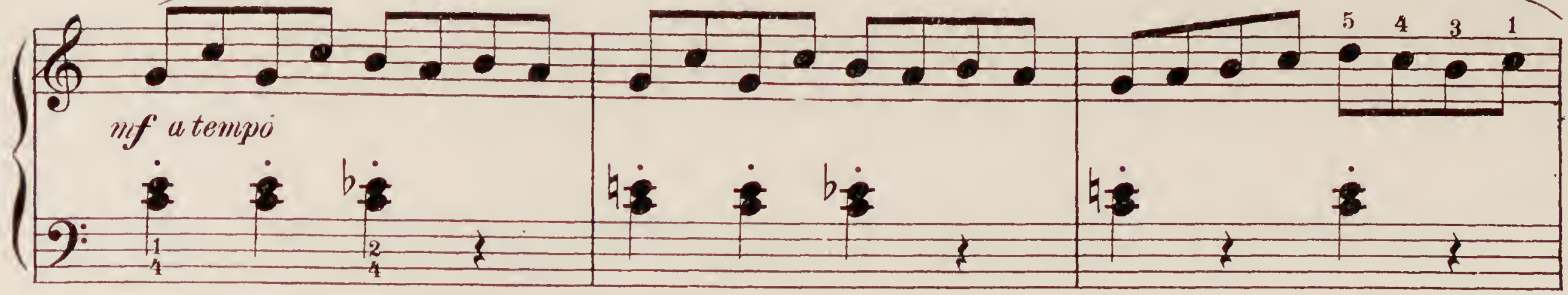
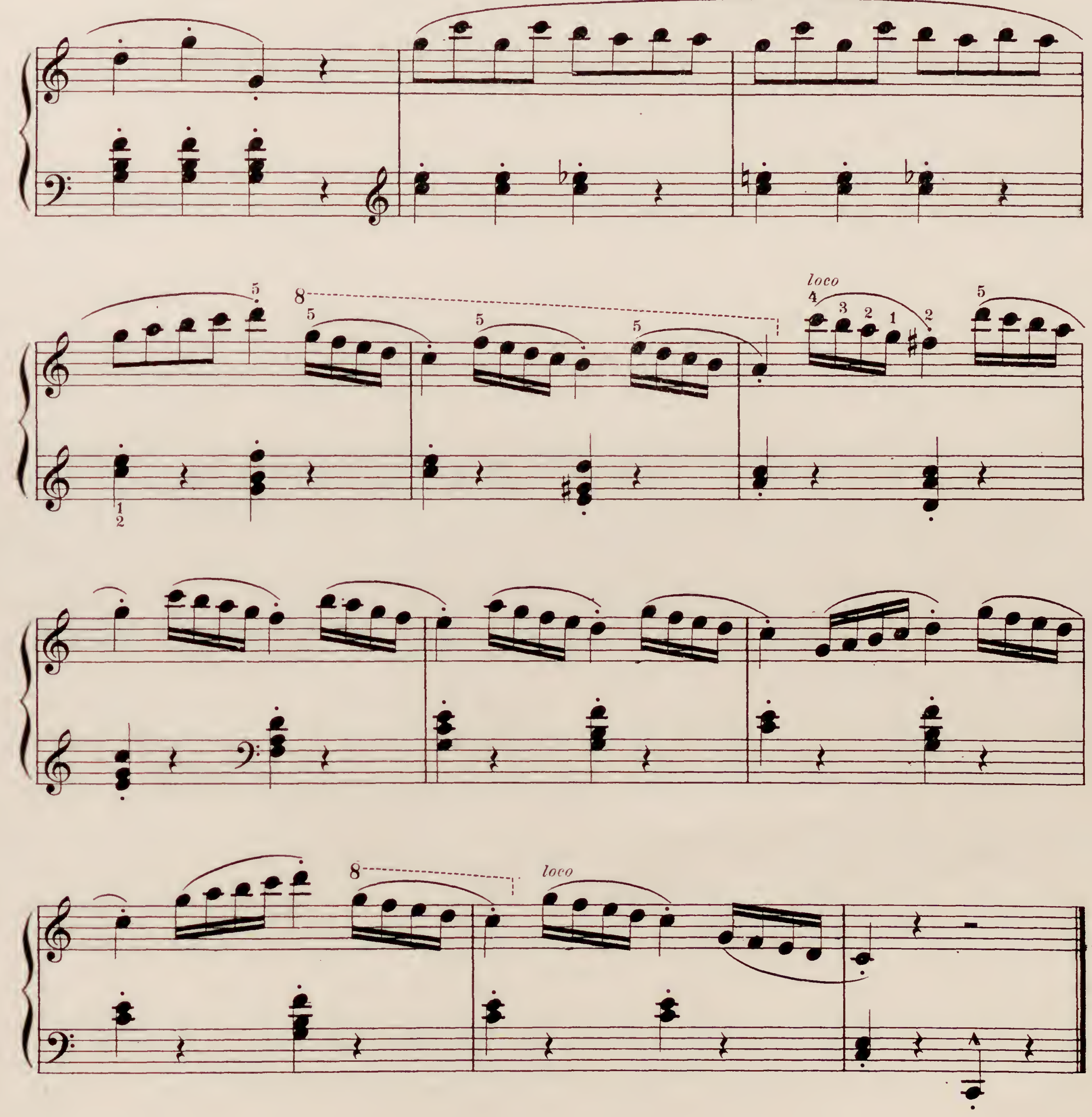
Uncle Remus
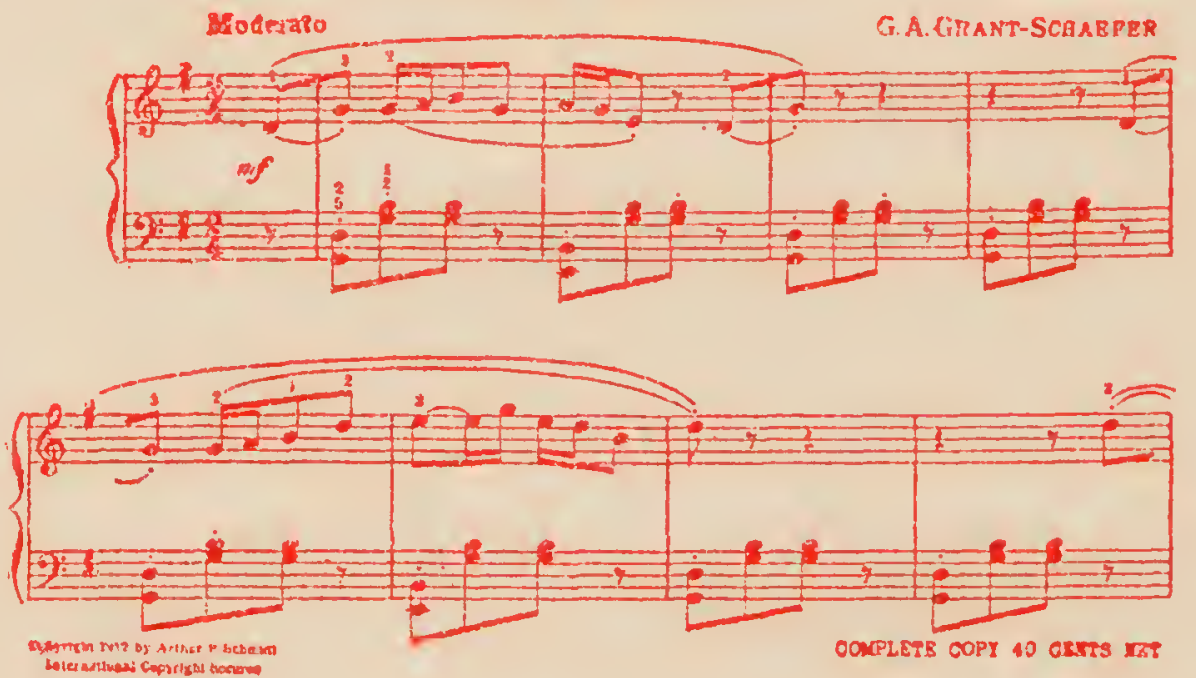

Old Southern Days
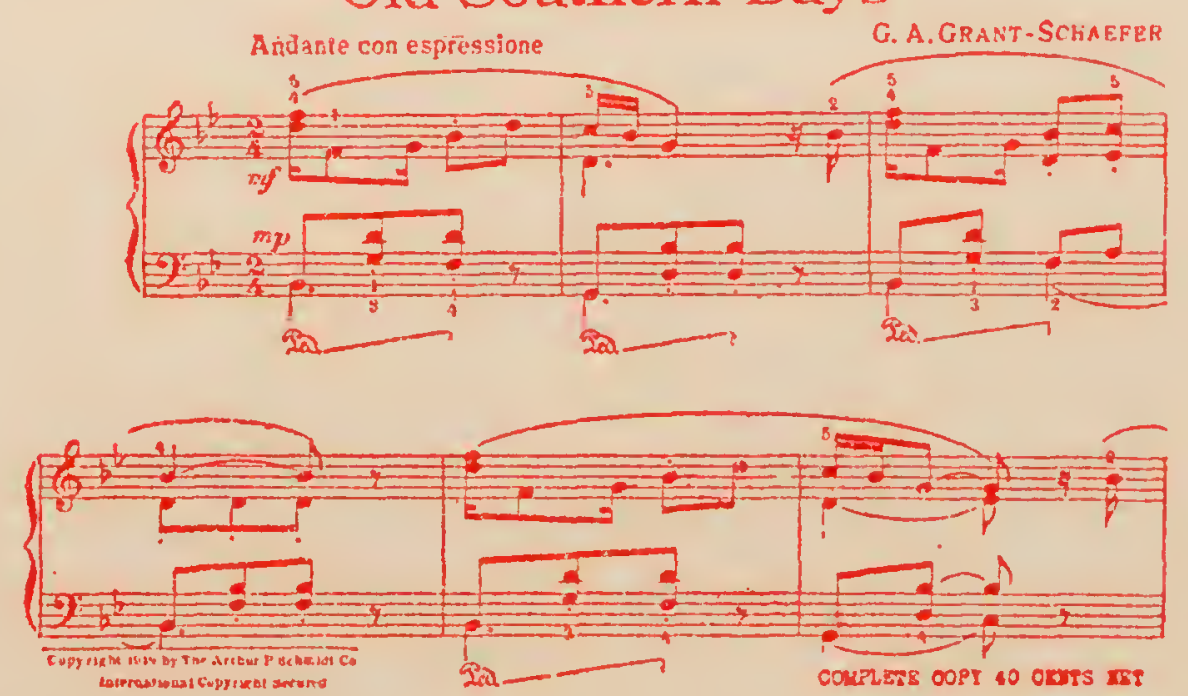

SOUTHWINDS
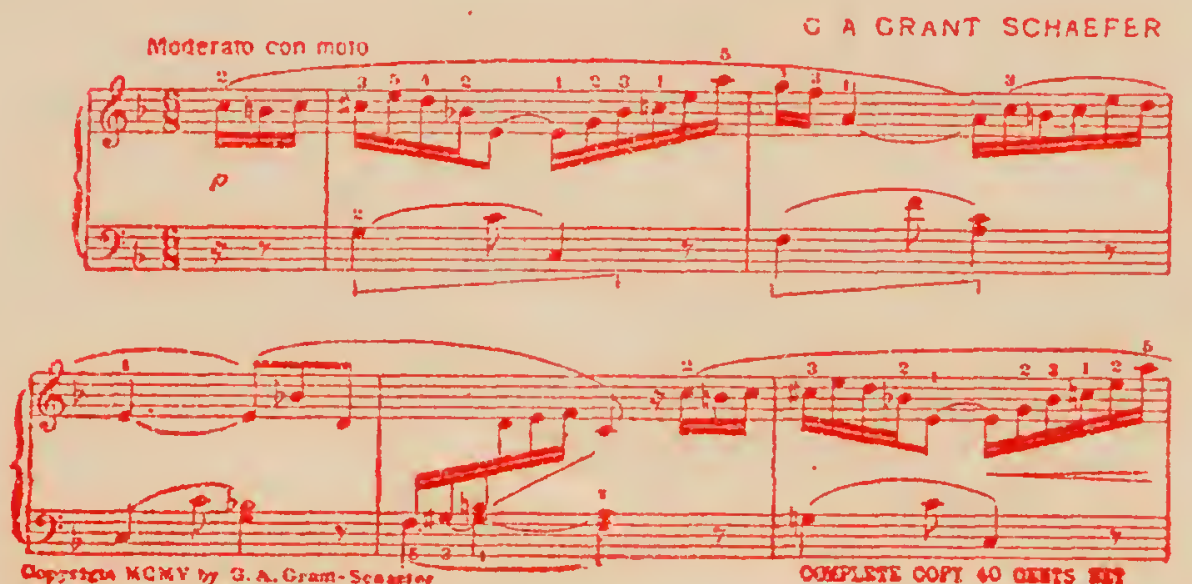

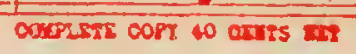

Springtime Caprice

(Staccato and Lightoess of Toucta
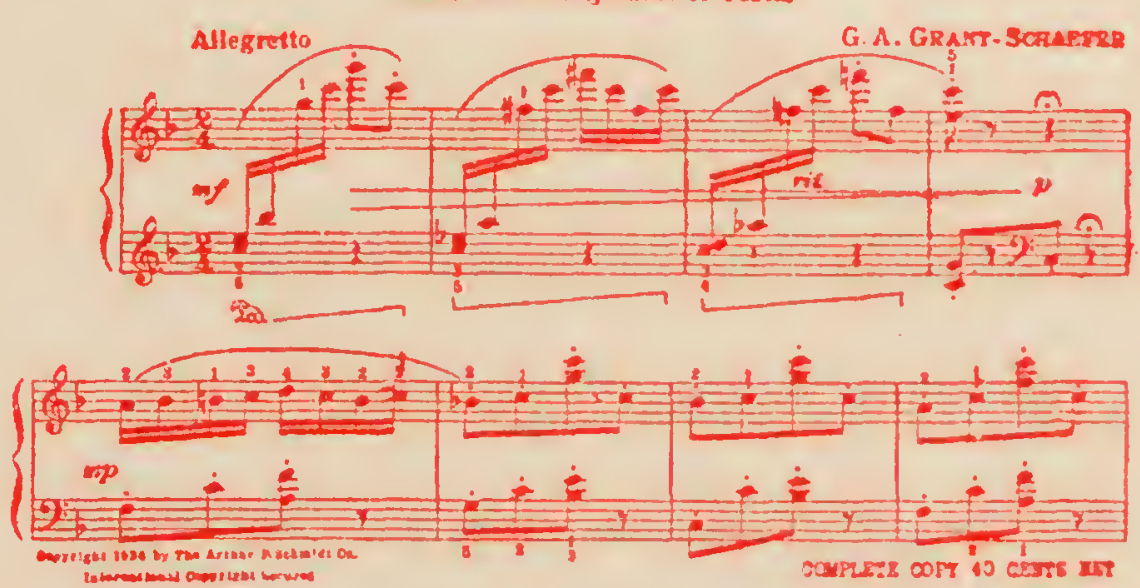

Butterflies.
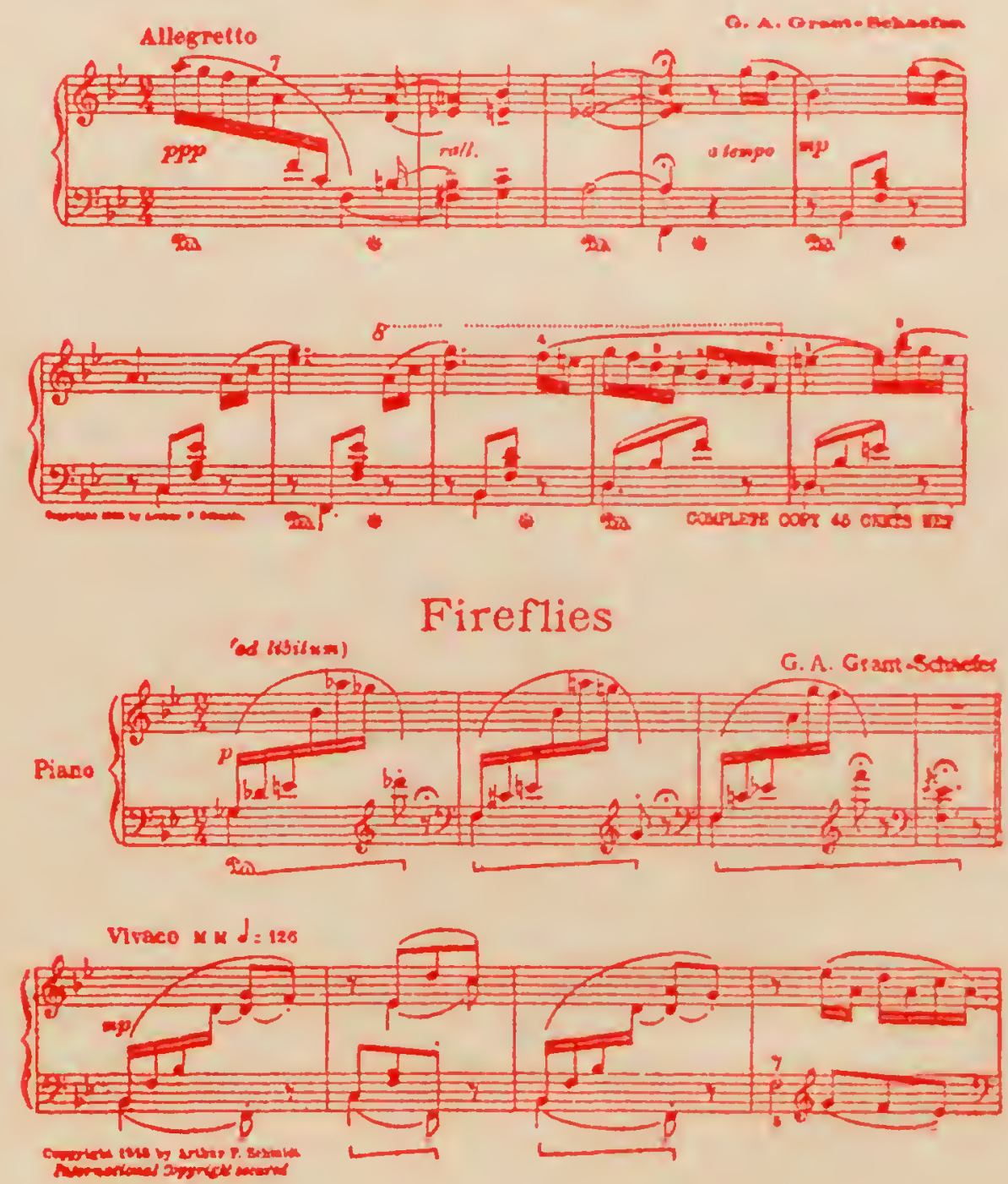